\section{POS0034 RADIOGRAPHIC ENTHESEAL LESIONS AT HIP AND PELVIC REGION ARE ASSOCIATED WITH LONGER DISEASE DURATION, HIGHER BMI AND MORE SEVERE SPINAL AND HIP RADIOGRAPHIC DAMAGE IN PATIENTS WITH ANKYLOSING SPONDYLITIS}

F. Wink ${ }^{1}$, T. Diemel ${ }^{2}$, S. Arends ${ }^{2}$, A. Spoorenberg ${ }^{2}{ }^{1}$ Medical Center Leeuwarden, Rheumatology, Leeuwarden, Netherlands; ${ }^{2}$ University Medical Center Groningen, Rheumatology and Clinical Immunology, Groningen, Netherlands

Background: Enthesitis is an important feature of ankylosing spondylitis (AS) and structural and inflammatory entheseal lesions (EL) are frequently present on ultrasound. Plain radiographs also provide good imaging of structural entheseal involvement1. Until now, little is known about the presence of structural EL at the hip and pelvic region and the association with patient characteristics in AS. Objectives: Our aim was to investigate the prevalence of radiographic $E L$ at the hip and pelvic region in AS patients compared to age and sex matched control subjects and to explore the relation with AS patient characteristics.

Methods: AS patients from the Groningen Leeuwarden Axial SpA (GLAS) cohort, included between November 2004 and December 2010, with available anteroposterior (AP) pelvis radiographs at baseline were included. All patients fulfilled the modified New York criteria for AS. Additionally, 100 randomly selected AP pelvis radiographs from age and sex matched control subjects were obtained from the radiology department of the University Medical Center Groningen. The sacroiliac joints of all radiographs were blinded and radiographs were scored independently by two trained observers unaware of patient characteristics and treatment. The entheseal sites scored were: trochanter major, trochanter minor, os ischium, crista iliaca, both left and right side. The following $3 \mathrm{EL}$ were scored: erosion/cortical irregularity, calcification and enthesophyte. Only lesions with absolute agreement between both observers were used for analyses. Radiographic spinal involvement was scored according to the modified Stoke AS Spine Score (mSASSS; range 0-72) and radiographic hip involvement according to the Bath AS Radiology Index (BASRI)-hip (range 0-4). Independent samples t test, Mann-Whitney U test, Chi-Square test, and Fisher Exact test were used to compare patient characteristics between patients with and without radiographic EL. Results: Of the 167 included AS patients, $117(70 \%)$ were male, mean age was $43 \pm 11$ years, $133(80 \%)$ were HLA-B27 positive and median symptom duration was 16 years (range 1-53). 127 (76\%) AS patients and 58 (58\%) controls showed EL, with 501 lesions in total of which $377(75 \%)$ in AS patients. AS patients showed significantly more lesions than controls at all 5 locations. Os ischii showed the most lesions in both AS patients and controls $(66 \%$ vs $53 \%, p<0.05)$. The most prevalent type of lesion in both groups was erosion/ cortical irregularity $(72 \%$ vs $51 \%, p<0.005)$. Enthesophytes were also more often observed in AS patients than in controls ( $31 \%$ vs $21 \%, p=0.07$ ). Prevalence of calcifications was low in both groups and not significantly different ( $5 \%$ vs $2 \%$, $\mathrm{p}=0.22$ ). AS patients with $E L$ were significantly older (mean 45.2 vs $35.1 \mathrm{yrs}$, $\mathrm{p}<0.005$ ) and had longer symptom duration (median 18 vs $7.5 \mathrm{yrs}, \mathrm{p}<0.005$ ) than patients without $\mathrm{EL}$. Furthermore, patients with $\mathrm{BMI}>25$ had significantly more often enthesophytes $(42 \%$ vs $16 \%, p<0.05)$ than patients with a normal BMI. Additionally, AS patients with EL had significantly more often radiographic spinal damage than patients without EL with median mSASSS total score 8.7 vs 1.0 $(p<0.005)$ and a trend toward significance for radiographic hip involvement (BASRl-hip score $\geq 2 ; p=0.06$ )

Conclusion: Radiographic EL at hip and pelvic region are significantly more prevalent in AS patients than in age and sex matched controls. AS patients with EL were significantly older, had longer symptom duration and more spinal radiographic damage than patient without EL. Furthermore, BMI >25 was associated with a higher prevalence of enthesophytes. These new findings contribute to the knowledge of entheseal involvement in AS.

REFERENCES:

[1] Voudouris et al. J Musculoskelet Neuronal Interact. 2003;3(1):89-100.

Disclosure of Interests: Freke Wink Consultant of: Abbvie, Thomas Diemel: None declared, Suzanne Arends: None declared, Anneke Spoorenberg Consultant of: Abbvie, Pfizer, MSD, UCB, and Novartis, Grant/research support from: Abbvie, Pfizer, UCB and Novartis.

DOI: 10.1136/annrheumdis-2021-eular.3057

\section{POS0035 \\ ONE IN TWENTY INFLAMMATORY BOWEL DISEASE PATIENTS WHO UNDERWENT ABDOMINOPELVIC COMPUTED TOMOGRAPHY HAVE UNDIAGNOSED AXIAL SPONDYLOARTHRITIS}

C. S. E. Lim ${ }^{1}$, L. Hamilton', S. Low², A. Toms², A. Macgregor ${ }^{1}$, K. Gaffney ${ }^{1}$.

Norfolk \& Norwich University Hospital, Rheumatology, Norwich, United Kingdom; ${ }^{2}$ Norfolk \& Norwich University Hospital, Radiology, Norwich, United Kingdom
Background: The diagnosis of axial spondyloarthritis (axSpA) is challenging and hindered by delay. There may be an opportunity to identify sacroiliitis for further rheumatology review in inflammatory bowel disease (IBD) patients who undergo Computed Tomography (CT) for non-musculoskeletal (MSK) indications. Objectives: To identify what proportion of IBD patients who underwent abdominopelvic CT for non-MSK indications have axSpA and to explore the role of an imaging strategy for identifying axSpA.

Methods: Abdominopelvic CT scans of verified IBD patients were identified retrospectively from eight years of imaging archive. Patients between 18-55 yrs were selected as having the highest diagnostic yield for axSpA. CT review (using criteria from a validated CT screening tool developed by $\mathrm{Chan}^{1}$ ) was undertaken by a trained radiology team for presence of CT-defined sacroilitis (CTSI). All CTSI patients were sent a screening questionnaire. Those with self-reported chronic back pain (CBP), duration $>3$ months, onset $<45$ years were invited for rheumatology review. This included a medical interview, physical examination (joint count, MASES, dactylitis count, BASMI), patient reported outcomes (BASDAI, BASFI, BASGI, Harvey-Bradshaw-Index, Partial-Mayo-Index), relevant laboratory tests (CRP, ESR, HLA-B27), axSpA protocol MRI, and remote review by a panel of experienced rheumatologists with a special interest in axSpA.

Results: CTSI was identified in 60 of 301 patients. Thirty-two (53\%) responded to the invitation to participate and $27(84 \%)$ were enrolled. Of these, eight had a pre-existing axSpA diagnosis and five did not report chronic back pain. Fourteen patients underwent rheumatological assessment; three of $14(21.4 \%[95 \%$ Cl: $4.7 \%, 50.8 \%])$ had undiagnosed axSpA. In total, 11 of $27(40.7 \%[95 \% \mathrm{Cl}$ $22.4 \%, 61.2 \%]$ ) patients had a rheumatologist verified diagnosis of axSpA

Conclusion: One in five patients (60/301) with IBD who underwent abdominopelvic CT for non-MSK indications have CTSI and at least one in five (11/60) have axSpA. Five percent $(3 / 60)$ were previously undiagnosed. This highlights a hidden disease burden and a potential strategy for identifying new cases.

\section{REFERENCES:}

[1] Chan J, Sari I, Salonen D, Inman RD, Haroon N. Development of a Screening Tool for the Identification of Sacroilitis in Computed Tomography Scans of the Abdomen. J Rheumatol 2016; 43(9); 1687-94.

Acknowledgements: We are indebted to Baljeet Dhillon and Shin Azegami for their assistance in the scoring of the CTSI.

Disclosure of Interests: Chong Seng Edwin Lim Grant/research support from: AbbVie, Louise Hamilton: None declared, Samantha Low: None declared, Andoni Toms: None declared, Alex MacGregor: None declared, Karl Gaffney Speakers bureau: AbbVie, Eli Lilly, Novartis, UCB Pharma, Consultant of: AbbVie, Eli Lilly, Novartis, UCB Pharma, Grant/research support from: AbbVie, Gilead, Eli Lilly, Novartis, UCB Pharma.

DOI: 10.1136/annrheumdis-2021-eular.2047

\section{POS0036 AN ARTIFICIAL INTELLIGENCE MODEL IN RHEUMATOLOGY: INTERPRETATION OF THE SACROILIAC JOINT GRAPHY IN ANKYLOSING SPONDYLITIS}

A. C. Genç ${ }^{1,2}$, Z. N. Kaya ${ }^{3}$, F. Turkoglu Genc ${ }^{4}$, L. Genc Kaya ${ }^{5}$, Z. Öztürk ${ }^{6}$, D. Karatas ${ }^{6}$, S. M. Turk ${ }^{6}$, E. Gönüllü ${ }^{6}{ }^{1}$ Geyve Government Hospital, Internal Medicine, Sakarya, Turkey; ${ }^{2}$ Bahcesehir University, Artificial Intelligence, Istanbul, Turkey; ${ }^{3}$ Saratoga High School, SHS AI Club, Saratoga, United States of America; ${ }^{4}$ Sakarya University, Internal Medicine, Sakarya, Turkey; ${ }^{5}$ Data Scientist, Data Scientist, Santa Clara, United States of America; ${ }^{6}$ Sakarya University, Rheumatology, Sakarya, Turkey

Background: There is an average of 8 years delay in the diagnosis of ankylosing spondylitis (AS). The most important danger of late diagnosis is that the disease can cause physical and functional disability (2). There is no specific diagnostic biomarker for AS. Sacroiliac joint (SIJ) radiography is frequently used in the diagnosis and follow-up of AS due to its easy accessibility and low cost. It can be classified as grade $0,1,2,3,4$, and these classes may not be sharply separated from each other (3)

Objectives: Interpretation of the SIJ radiography may differ from physician to physician. In fact, the same physician may interpret it differently at different times (3). We wanted to find a solution to the intraobserver disagreement problem with the artificial intelligence model.

Methods: The SIJ radiography of 590 patients who applied to our center were divided into 3 categories as right and left, separately, grade 0 , grade 1-2, grade 3-4, and an educational data set was prepared for the object recognition method. 488 images were augmented through noise from 490 images in the training data. 242 articular objects were trained for grade 0,278 for grade 1-2, and 1426 for grade 2-3. The model was tested with 100 images for 36 joint objects for grade 0,29 for grade 1-2, and 135 for grade 3-4 to create a computer vision-artificial intelligence model (image 1).

Results: Training performance is $70 \%$ for grade $0, \% 63$ for grade $1-2, \% 90$ for grade $3-4$ and test performance is $\% 52$ for grade $0, \% 24$ for grade $1-2, \% 86$ 